\title{
Biocatalytic synthesis of ethyl (R)-2-hydroxy-4- phenylbutyrate with a newly isolated Rhodotorula mucilaginosa CCZU-G5 in an aqueous/organic biphasic system
}

Liqun Wang ${ }^{1 *}$, Junjie Miao ${ }^{1}$, Zhongqiang Wang ${ }^{2}$, Lijuan Wang ${ }^{1}$, Qing Qing ${ }^{1}$ and Shang-Tian Yang ${ }^{2 *}$

\begin{abstract}
Background: Optically active ethyl (R)-2-hydroxy-4-phenylbutyrate $[(R)-\mathrm{HPBE}]$ is an important chiral building block for the synthesis of angiotensin-converting enzyme (ACE) inhibitors. It is reported that microbial or enzymatic reduction of ethyl 2-oxo-4-phenyl-butyrate (OPBE) is an attractive way to produce optically active (R)-HPBE.

Results: The asymmetric reduction of OPBE to synthesize optically active (R)-HPBE with a newly isolated Rhodotorula mucilaginosa CCZU-G5 as catalyst was investigated in an aqueous/organic solvent biphasic system. R. mucilaginosa CCZU-G5 showed a good tolerance (the metabolic activity retention $>80 \%$ ) in the biphasic system composed of aqueous buffer and organic solvent with a $\log P$ value over 4.6. Isooctane was found to be the most suitable organic phase solvent. In the biphasic system, the volumetric phase ratio, OPBE concentration, cell concentration, reaction temperature, and buffer $\mathrm{pH}$ were optimized. Under the optimum conditions (volumetric phase ratio: 1/1, OPBE concentration: $100 \mathrm{mM}$, cell concentration: $0.075 \mathrm{~g} / \mathrm{mL}, \mathrm{pH} 7.5,35^{\circ} \mathrm{C}$ ), the final yield and the optical purity of (R)-HPBE reached $98.3 \%$ and $>99.0 \%$ enantiomeric excess (ee), respectively, after $12 \mathrm{~h}$ of reaction.
\end{abstract}

Conclusions: All the results suggested that the OPBE-reducing enzymes in a newly isolated R. mucilaginosa cells possess highly stable and excellent stereoselectivity by establishing an aqueous/organic biphasic system.

Keywords: Rhodotorula mucilaginosa CCZU-G5; Biphasic system; Isooctane; Ethyl (R)-2-hydroxy-4-phenylbutyrate

\section{Background}

Optically active ethyl (R)-2-hydroxy-4-phenylbutyrate $[(R)-\mathrm{HPBE}]$ is an important chiral building block for the synthesis of angiotensin-converting enzyme (ACE) inhibitors such as benazepril, enalapril, and lisinopril [1]. In general, ACE inhibitors prevent the conversion of the precursor decapeptide angiotensin I to the powerful vasoconstrictor substance angiotensin II and have been demonstrated to be potent antihypertensive drugs [2]. In recent years, various chemical and biological approaches for $(R)$-HPBE preparation have been reported, mainly in two ways: kinetic resolution and synthesis. However, chemical synthesis usually involves multiple

\footnotetext{
* Correspondence: wangliqun567@gmail.com; yang.15@osu.edu ${ }^{1}$ School of Pharmaceutical Engineering and Life Sciences, Changzhou University, 1 Ge Hu Road, Jiangsu 213164, China

${ }^{2}$ William G. Lowrie Department of Chemical and Biomolecular Engineering, The Ohio State University, 140 W 19th Ave, Columbus, OH 43210, USA
}

steps and stringent reaction conditions [3], and resolution methods are limited by theoretical maximum yield of only $50 \%$ [4].

Microbial or enzymatic reduction of ethyl 2-oxo-4phenyl-butyrate (OPBE) is an attractive way to produce optically active $(R)$-HPBE, since OPBE can be easily synthesized and is relatively cheap. Several biocatalysts have been used in the synthesis of $(R)$-HPBE, including the hydrolysis and transesterification catalyzed by lipase [5] and the reduction of OPBE catalyzed by isolated dehydrogenase [6] and whole cells $[7,8]$. Since the reduction reaction requires stoichiometric amounts of nicotinamide cofactors, whole cells rather than isolated enzymes were used preferentially to avoid enzyme purification and cofactor addition [9].

In the past decade, however, only a few microorganisms have been reported as efficient biocatalysts in the reduction of OPBE to $(R)$-HPBE. Chadha et al. reported 
that the enantioselective reduction of OPBE to $(R)-\mathrm{HPBE}$ could be achieved by using cell-free aqueous extracts of the callus of Daucus carota (wild carrot) with a high yield (90\%) and enantiomeric excess (ee) (99\%) [10]. However, their process required a high cell/substrate ratio of 100:1, a large amount of cells, and a long reaction time of 10 days. Dao et al. and Lacerda et al. reported the successful reduction of OPBE with Pichia angusta and Saccharomyces cerevisiae, respectively, to give $(R)$ HPBE with a moderate enantioselectivity $(81 \%$ ee $)[7,11]$. Recently, Chen et al. described the successful preparation of (R)-HPBE with favorable ee (99\%) and yield (92\%) by using Candida boidinii CIOC21 [12]. However, the relatively low concentrations of the substrate (around $4.1 \mathrm{~g} / \mathrm{L}$ ) and product (around $3.8 \mathrm{~g} / \mathrm{L}$ ) in their process would restrict its application in large-scale production. In addition, Zhang et al. used Candida krusei SW2026 to produce (R)-HPBE from $20 \mathrm{~g} / \mathrm{L}$ of OPBE with excellent ee (97.4\%) and a moderate yield (82\%) [8].

Recently, we have isolated a new yeast strain Rhodotorula mucilaginosa CCZU-G5 from vineyard soil samples and used it in preparing $(R)$-HPBE with high ee and yield. However, a severe substrate inhibition was observed when the tested OPBE concentration in an aqueous single-phase system was high due to the high hydrophobicity of the substrate and its toxicity to the cells, and the highest substrate concentration that the bacterium could transform was only $50 \mathrm{mM}$. The aqueous/organic solvent biphasic system is a good alternative to resolve the aforementioned problems occurred in the aqueous system. The organic solvent phase in the biphasic system acts as a substrate reservoir and prevents the cells in the aqueous phase from being damaged by high substrate concentration. This biphasic system has attracted great attention over the past few decades, and several successful examples have been reported [13-15].

In this study, resting cells of $R$. mucilaginosa CCZU-G5 were used as biocatalysts for asymmetric reduction of OPBE in an aqueous/organic solvent biphasic system. Various parameters such as substrate concentration, cell concentration, reaction temperature, and $\mathrm{pH}$ were investigated and optimized to improve the yield and optical purity (ee) of $(R)$-HPBE. Compared to the monophasic aqueous system, the asymmetric reduction of OPBE in the aqueous/organic solvent biphasic system gave excellent $e e$ and a much higher yield due to reduced substrate and product inhibition. To our best knowledge, this is the first study using $R$. mucilaginosa cells for high-yield and high-purity production of $(R)$-HPBE.

\section{Methods}

Chemicals

(R)-HPBE was purchased from Sigma-Aldrich Chemical Co. (St. Louis, MO, USA) OPBE was supplied by Wujin
Fine Chemical Factory Co., Ltd. (Changzhou, Jiangsu, China). All other reagents and solvents were commercially available, and were of analytical grade purity.

\section{Microbial strain and cultivation conditions}

The yeast $R$. mucilaginosa CCZU-G5 was isolated from vineyard soil samples and preserved in China General Microbiological Cultures Collection Center (CGMCC 6328). It was grown in the following medium: glucose $20 \mathrm{~g} /$ $\mathrm{L}$, yeast extract $10 \mathrm{~g} / \mathrm{L}$, peptone $15 \mathrm{~g} / \mathrm{L},\left(\mathrm{NH}_{4}\right)_{2} \mathrm{SO}_{4} 1 \mathrm{~g} / \mathrm{L}$, $\mathrm{MgSO}_{4} \cdot 7 \mathrm{H}_{2} \mathrm{O} 1 \mathrm{~g} / \mathrm{L}, \mathrm{pH}$ 7.0. The strain was incubated aerobically at $30^{\circ} \mathrm{C}$ and $180 \mathrm{rpm}$ in $500-\mathrm{mL}$ Erlenmeyer flasks with $70 \mathrm{~mL}$ sterilized medium. After $72 \mathrm{~h}$ of growth, the cells were harvested by centrifugation $(8,000 \times g$ for $10 \mathrm{~min})$ at $4^{\circ} \mathrm{C}$, washed twice with $0.85 \%(w / v) \mathrm{NaCl}$, and then stored at $4^{\circ} \mathrm{C}$ for further use.

\section{Bioconversion in monophasic aqueous system}

The reduction of OPBE in the aqueous system was conducted in a 50-mL Erlenmeyer flask capped with a septum. Two grams of wet cells was suspended in $20.0 \mathrm{~mL}$ phosphate-buffered saline (PBS) (0.1 M, pH 7.0) with $1 \mathrm{~g}$ glucose and $0.4 \mathrm{mmol} \mathrm{OPBE}$. The cell suspensions were subsequently incubated in a rotary incubator at $35^{\circ} \mathrm{C}$ and $180 \mathrm{rpm}$. The mixture was centrifuged to remove the cells at different time intervals, and the supernatant was extracted three times with ethyl acetate and dried over anhydrous $\mathrm{Na}_{2} \mathrm{SO}_{4}$ for gas chromatography (GC) analysis.

\section{Tolerance assay of $R$. mucilaginosa CCZU-G5 in biphasic systems}

Four grams of harvested cells was suspended in $100 \mathrm{~mL}$ PBS (0.1 M, pH 7.0) to give a final concentration of $0.04 \mathrm{~g} / \mathrm{mL}$. Ten milliliters of the cell suspension was added to $10 \mathrm{~mL}$ of each of the different organic solvents in a 50-mL Erlenmeyer flask capped with a septum. The cell suspension $(0.04 \mathrm{~g} / \mathrm{mL})$ in PBS without any organic solvent was used as a control. All cell suspensions were subsequently incubated in a rotary incubator at $30^{\circ} \mathrm{C}$ and $180 \mathrm{rpm}$ for $24 \mathrm{~h}$. The cell suspensions were then centrifuged $(8,000 \times g$ for $10 \mathrm{~min})$ at $4^{\circ} \mathrm{C}$. Then the cells were transferred to $10 \mathrm{~mL}$ of $20 \mathrm{~g} / \mathrm{L}$ glucose and incubated at $30^{\circ} \mathrm{C}$ and $180 \mathrm{rpm}$. After $4 \mathrm{~h}$, the suspensions were centrifuged, and the supernatants were analyzed using a spectrophotometer to determine the concentration of glucose through DNS method to obtain the amount of consumed glucose [16]. The metabolic activity retention is defined as the ratio of the amount of glucose consumed by the cells pretreated in the biphasic system to that consumed by the cells pretreated in PBS.

\section{Bioconversion in biphasic systems}

Experiments examining the asymmetric reduction of OPBE in biphasic systems were performed in $50-\mathrm{mL}$ 
Erlenmeyer flasks. A certain amount of wet yeast cells were suspended in $0.1 \mathrm{M} \mathrm{PBS}$ and mixed with $10 \mathrm{~mL}$ organic solvent containing OPBE to form the aqueous/organic biphasic system (shown in Scheme 1). The flasks were incubated in a rotary shaker at $180 \mathrm{rpm}$ and a specified temperature. Due to their high hydrophobicity, the substrate OPBE and the product $(R)$-HPBE were primarily partitioned in the organic phase, while the cells were mainly suspended in the aqueous phase. Unless otherwise specified, the concentration of the substrate and product were calculated based on the volume of the whole biphasic system. Six hundred-microliter aliquots of the sample were withdrawn from the organic phase at different time intervals: $100 \mu \mathrm{L}$ aliquots were mixed with $100 \mu \mathrm{L}$ dodecane as the internal standard for GC analysis, and $500 \mu \mathrm{L}$ aliquots were used for high-performance liquid chromatography (HPLC) analysis.

\section{Analytical methods}

The concentrations of OPBE and HPBE were determined with a gas chromatography. (GC-950, Shanghai Haixin Chromatographic Instrument Co., Ltd., Shanghai, China) equipped with a flame ionization detector and a SE-30 capillary column (30 m, i.d. $0.5 \mathrm{~mm})$. The $(R)$-HPBE and $(S)$-HPBE were analyzed using an Agilent 1260 HPLC system (Sta. Clara, CA, USA) equipped with a Chiralcel OD-H column $(4.6 \mathrm{~mm} \times 250 \mathrm{~mm}, 5 \mu \mathrm{m}$, Diacel, Hyogo, Japan) using $n$-hexane:isopropanol $(95: 5, v / v)$ as eluent at a flow rate of $1.0 \mathrm{~mL} / \mathrm{min}$. The detection was performed at $225 \mathrm{~nm}$.

The ee value was calculated as follows:

$$
e e=\frac{[R]-[S]}{[R]+[S]} \times 100 \%
$$

where $[R]$ and $[S]$ are the peak areas of $(R)$-HPBE and $(S)$-HPBE, respectively. The yield of $(R)$-HPBE was calculated from the final molar concentration of the product, $C_{\mathrm{p}}$, and the initial molar concentration of the substrate, $C_{\mathrm{s}}$ as follows:

$$
\text { Yield }=\frac{c_{\mathrm{p}}}{c_{\mathrm{s}}} \times 100 \%
$$

\section{Results and discussion \\ Tolerance of $R$. mucilaginosa CCZU-G5 in different biphasic systems}

The metabolic activity of cells could be affected by the organic solvent in a biphasic system $[16,17]$. It has been reported that solvents with a higher $\log P$ are more hydrophobic and thus more advantageous for enzymatic reactions [8]. In this work, 11 organic solvents with different $\log P$ values ranging from 0.68 to 5.6 were studied and compared for their toxicity to $R$. mucilaginosa CCZU-G5. As the toxicity indicator, cell viability or metabolic activity retention $(R \%)$ in the various biphasic systems was evaluated and the results were shown in Table 1 . In general, there was a positive correlation between activity retention and the $\log P$ value of the organic solvent. Satisfactory metabolic activity retention over $80 \%$ was attained when the $\log P$ value of the solvent was over 4.6. The maximal metabolic activity retention reached $97.8 \%$ in the water/ndecane system. The metabolic activity retention was low when the $\log P$ value of the solvent was lower than 3.2. For example, it was just $14.7 \%$ in the water/ethyl acetate biphasic system because the cell membrane would be destroyed by the polar organic solvent with a low log $P$ value [18].

\section{Selection of organic solvents}

The asymmetric reduction of OPBE to $(R)$-HPBE with resting cells of $R$. mucilaginosa CCZU-G5 in an aqueous medium has been optimized in our previous work (20 mM OPBE, yield $76.3 \%$, ee $99.2 \%$, productivity $6.8 \mathrm{~g} / \mathrm{L} /$ day). The aqueous systems supported a desirable ee value, but the highest substrate concentration that could be transformed

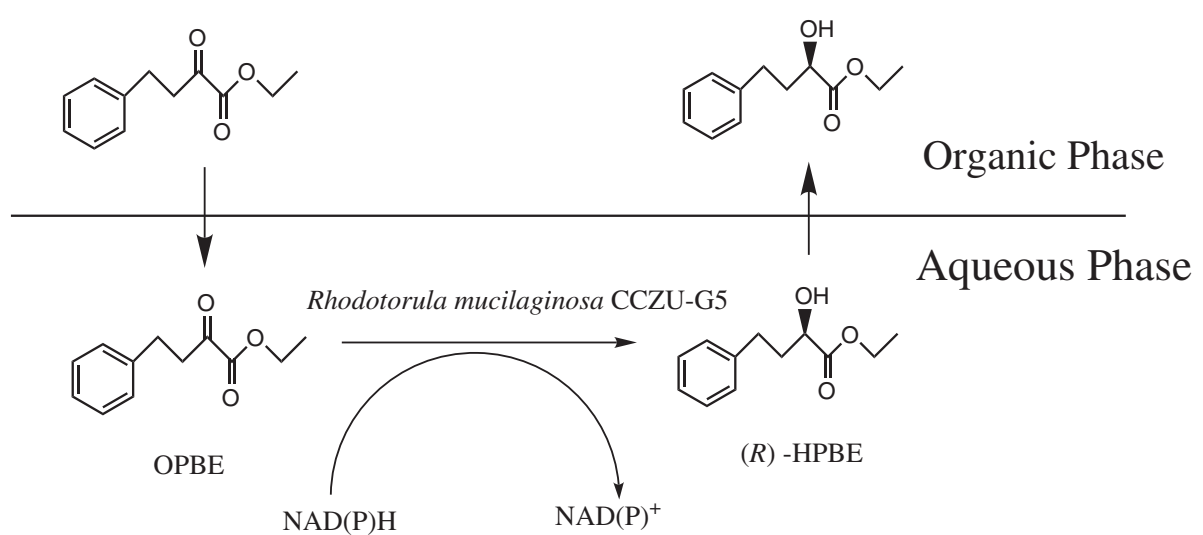

Scheme 1 Mechanism of $R$. mucilaginosa CCZU-G5 for asymmetric reduction of OPBE to $(R)$-HPBE biphasic system. 
Table 1 Tolerance and asymmetric reduction of OPBE to (R)-HPBE with R. mucilaginosa CCZU-G5 in different organic/aqueous biphasic systems

\begin{tabular}{lllll}
\hline Organic solvent & Log $\boldsymbol{P}$ & $\begin{array}{l}\text { Metabolic activity } \\
\text { retention (\%) }\end{array}$ & Yield (\%) $^{\mathbf{b}}$ & ee (\%) \\
\hline EtOAC & 0.68 & $14.5 \pm 0.6$ & $11.3 \pm 0.7$ & 16.5 \\
Butyl acetate & 1.7 & $17.1 \pm 0.7$ & $14.3 \pm 1.3$ & 18.4 \\
Benzene & 2.0 & $17.5 \pm 0.6$ & $36.1 \pm 1.1$ & 45.5 \\
Toluene & 2.5 & $22.3 \pm 0.7$ & $44.1 \pm 1.0$ & 49.4 \\
Cyclohexane & 3.2 & $50.4 \pm 1.3$ & $53.1 \pm 1.5$ & 68.9 \\
n-Hexane & 3.5 & $67.2 \pm 0.9$ & $69.3 \pm 0.5$ & $>99.0$ \\
n-Heptane & 4.0 & $70.5 \pm 0.8$ & $89.3 \pm 0.4$ & $>99.0$ \\
n-Octane & 4.5 & $78.8 \pm 0.7$ & $90.3 \pm 0.4$ & $>99.0$ \\
Isooctane & 4.6 & $80.1 \pm 0.6$ & $98.1 \pm 0.3$ & $>99.0$ \\
n-Hydride & 5.1 & $92.2 \pm 0.4$ & $63.1 \pm 0.3$ & $>99.0$ \\
n-Decane & 5.6 & $98.0 \pm 0.4$ & $52.8 \pm 0.9$ & $>99.0$ \\
\hline
\end{tabular}

a Metabolic activity retention $(R)$ of $R$. mucilaginosa CCZU-G5: $0.4 \mathrm{~g}$ wet cells suspended in $10 \mathrm{~mL}$ PBS buffer $(0.1 \mathrm{M}, \mathrm{pH} 7.0)$ was mixed with $10 \mathrm{~mL}$ of different organic solvents incubated at $30^{\circ} \mathrm{C}$ and $180 \mathrm{rpm}$ for $24 \mathrm{~h}$. The cell suspension in PBS without any organic solvent was used as a control. Then the harvested cells were transferred to $10 \mathrm{~mL}$ of $20 \mathrm{~g} / \mathrm{L}$ glucose and incubated at $30^{\circ} \mathrm{C}$ and $180 \mathrm{rpm}$ for $4 \mathrm{~h}$. ${ }^{\mathrm{b}}$ Reaction conditions: $2.0 \mathrm{~g}$ wet cells suspended in $10 \mathrm{~mL}$ PBS buffer $(0.1 \mathrm{M}, \mathrm{pH} 7.0)$ containing $1.0 \mathrm{~g}$ glucose was mixed with $10 \mathrm{~mL}$ of an organic solvent containing $2 \mathrm{mmol} \mathrm{OPBE}$ and incubated at $30^{\circ} \mathrm{C}$ and $180 \mathrm{rpm}$ for $24 \mathrm{~h}$.

with $0.1 \mathrm{~g} / \mathrm{mL}$ cell was merely $50 \mathrm{mM}$. To enhance the substrate concentration and overcome the substrate-tolerance obstacle [14,19], the reaction was explored in the aqueous/ organic biphasic system. With the addition of organic solvents, the solubility of the substrate could be enhanced. Besides, the hydrophilic microbial cells (in aqueous phase) could be separated from the hydrophobic substrate and the product in the organic phase. The selection of the organic solvent as substrate and product carrier in an aqueous/organic solvent biphasic system is based mainly on its biocompatibility towards the biocatalyst and adequate solubility of both substrate and product [20]. Therefore, the influence of organic solvents on the catalytic activity and enantioselectivity was studied in 11 different biphasic systems with different $\log P$ values ranging from 0.68 to 5.6 . In general, there was a positive correlation between the product yield and the $\log P$ value of organic solvent (Table 1), with the exceptions of $n$-hydride and $n$-decane, which have $\log P$ values of over 5 but gave a relatively low product yield. The maximal yield of $98.1 \%$ was achieved in the aqueous/isooctane biphasic system. The yield decreased significantly in the organic solvents with lower $\log P$ values such as butyl acetate and EtOAC, which gave a poor yield of $11.3 \%$. The ee values of $(R)$-HPBE were higher than $99.0 \%$ when the $\log P$ values of the organic solvents were more than 3.2. Considering the yield and the $e e$ value, the aqueous/isooctane biphasic system was selected for further study.

\section{Effects of phase volume ratio}

The volumetric phase ratio influences the phase interfacial area between two phases, which, in turn, affects biotransformation in the biphasic systems [21]. The effects of the volume ratio of the aqueous phase to the organic phase $\left(V_{\mathrm{aq}} / V_{\text {org }}\right)$ on the asymmetric reduction of $\mathrm{OPBE}$ were studied in the aqueous/isooctane biphasic system. A fixed volume $(10 \mathrm{~mL})$ of isooctane was mixed with different volumes ( 2 to $20 \mathrm{~mL}$ ) of the aqueous phase containing 2 g cells to form biphasic aqueous/isooctane system. As seen in Figure 1, the product yield increased when the phase ratio $\left(V_{\mathrm{aq}} / V_{\text {org }}\right)$ went up from 0.2 to 0.8 due to the increased availability of substrate molecules in aqueous phase. With a phase ratio of 0.8 to 1.2 , the maximum yield of $(R)-\mathrm{HPBE}$ (98.1\%) was achieved. However, the yield decreased when the phase volume ratio was higher than 1.2 probably because of the increased sensitivity to the substrate toxicity when the cells were diluted. Although the yield was highly dependent on the phase volume ratio, excellent optical purity of the product (ee $>99.0 \%$ ) was observed in the aqueous/isooctane biphasic system, regardless of the phase ratio.

\section{Effects of temperature}

It is well known that the reaction temperature is an important factor affecting the catalytic characteristics such as the activity, enantioselectivity, and stability of a biocatalyst [22]. As shown in Figure 2, the product yield increased gradually when the temperature rose from $25^{\circ} \mathrm{C}$ to $35^{\circ} \mathrm{C}$. However, at higher temperatures, the yield decreased significantly with increasing the temperature, indicating thermal deactivation of the cells at higher temperatures. The $e e$ value was not significantly affected by temperature and remained above $99.0 \%$ at all temperatures studied.

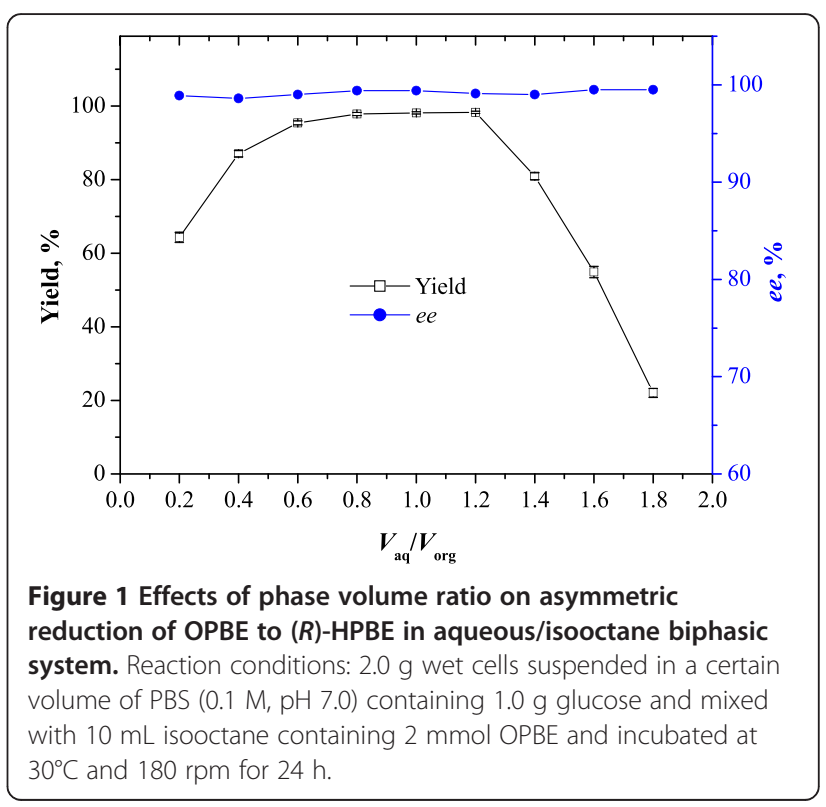




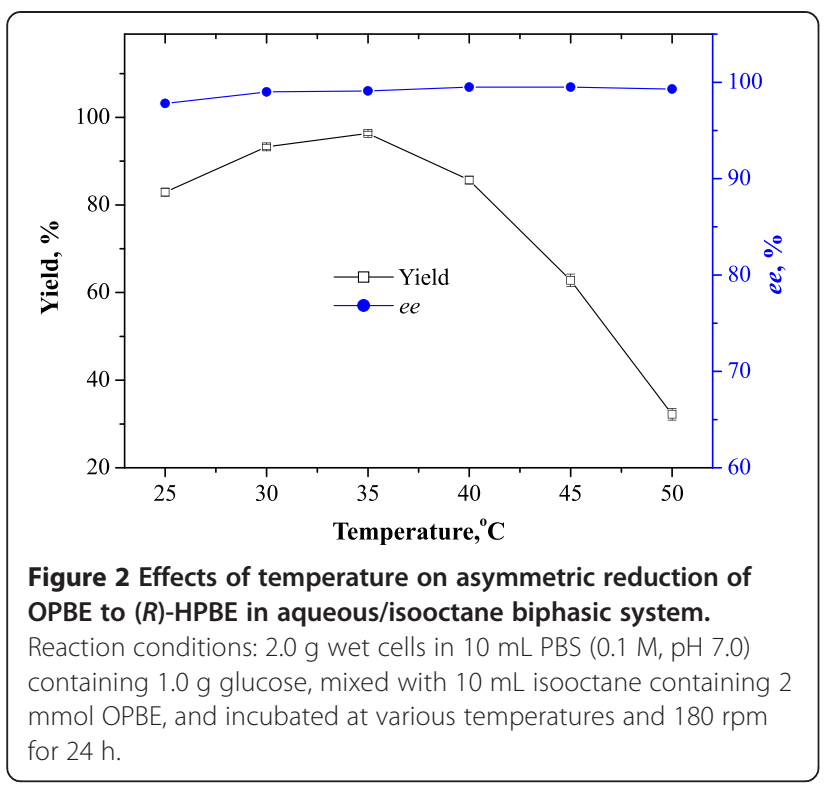

\section{Effects of $\mathrm{pH}$}

The reaction $\mathrm{pH}$ plays a crucial role in bioreduction and influences not only enzymatic enantioselectivity and activity but also the regeneration of coenzymes [23-25]. In addition, variations in the $\mathrm{pH}$ may also alter the ionic state of substrates and the enzymes involved in the reactions [26]. Figure 3 shows the effects of aqueous medium $\mathrm{pH}$ (over the range of 5.5 to 8.0 ) on the asymmetric reduction of OPBE to $(R)$-HPBE. The highest product yield was obtained at $\mathrm{pH}$ 7.5. The product yield decreased dramatically at lower or higher $\mathrm{pH}$ values. It is clear that $\mathrm{pH}$ could exert a tremendous influence on the reaction rate and yield in the aqueous/isooctane system. However, the

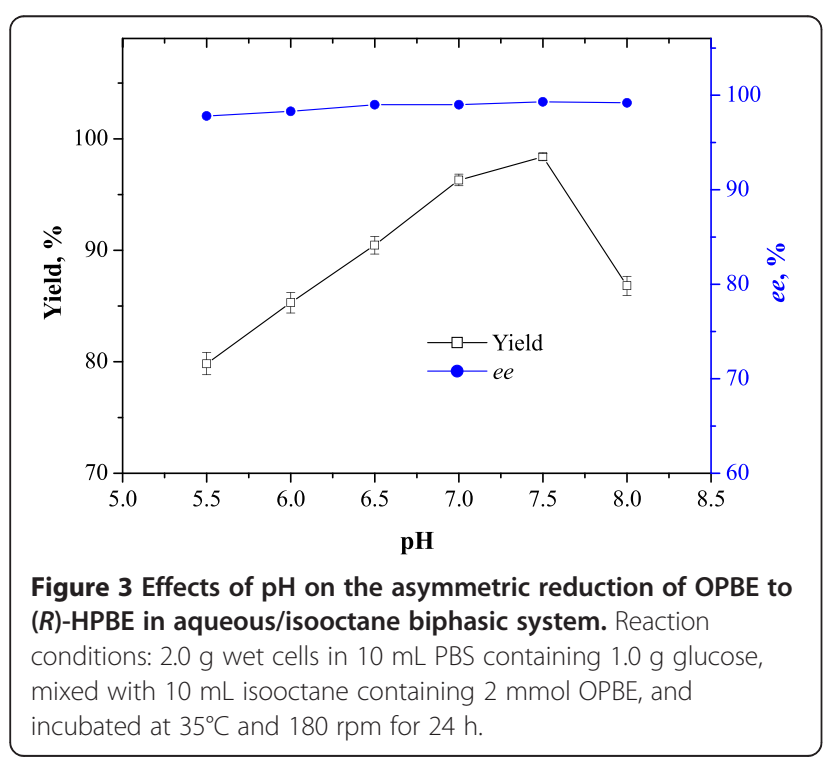

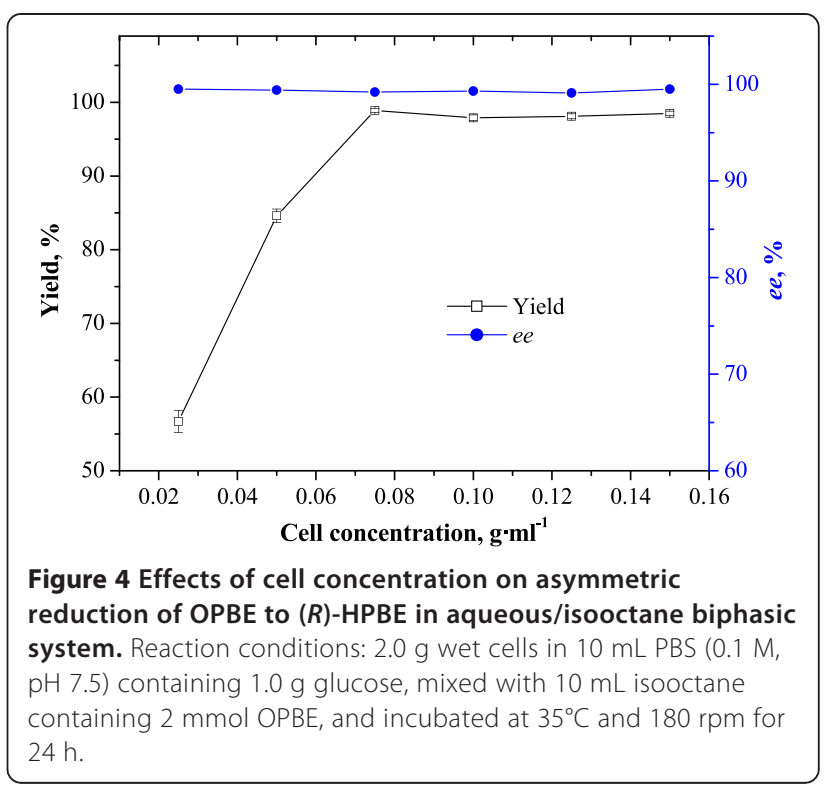

ee value was not significantly affected by the $\mathrm{pH}$ and remained above $99.0 \%$ for all $\mathrm{pH}$ values studied. Based on the results, $\mathrm{pH} 7.5$ was the optimum for the reaction.

\section{Effects of cell concentration}

The concentration of biocatalyst is an important factor in enzymatic reactions because it affects both enantioselectivity and reaction rate [19]. In order to investigate the effects of cell concentration on OPBE reduction in aqueous/isooctane system, the $e e$ and yield of the product were determined at different cell concentrations. As shown in Figure 4, the cell concentration in the aqueous phase had no effect on the ee value but had a marked

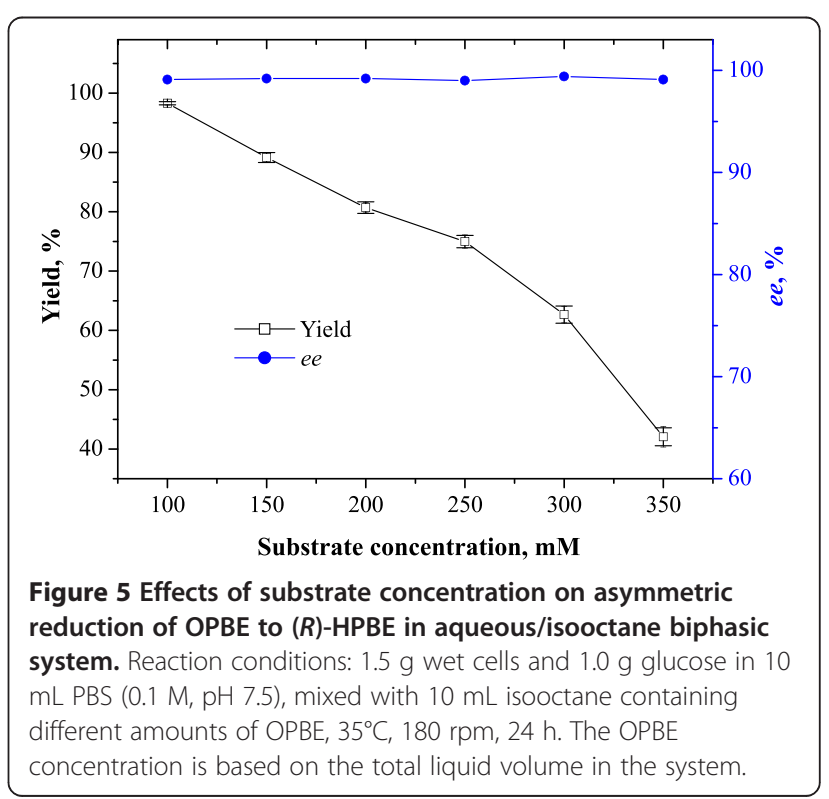




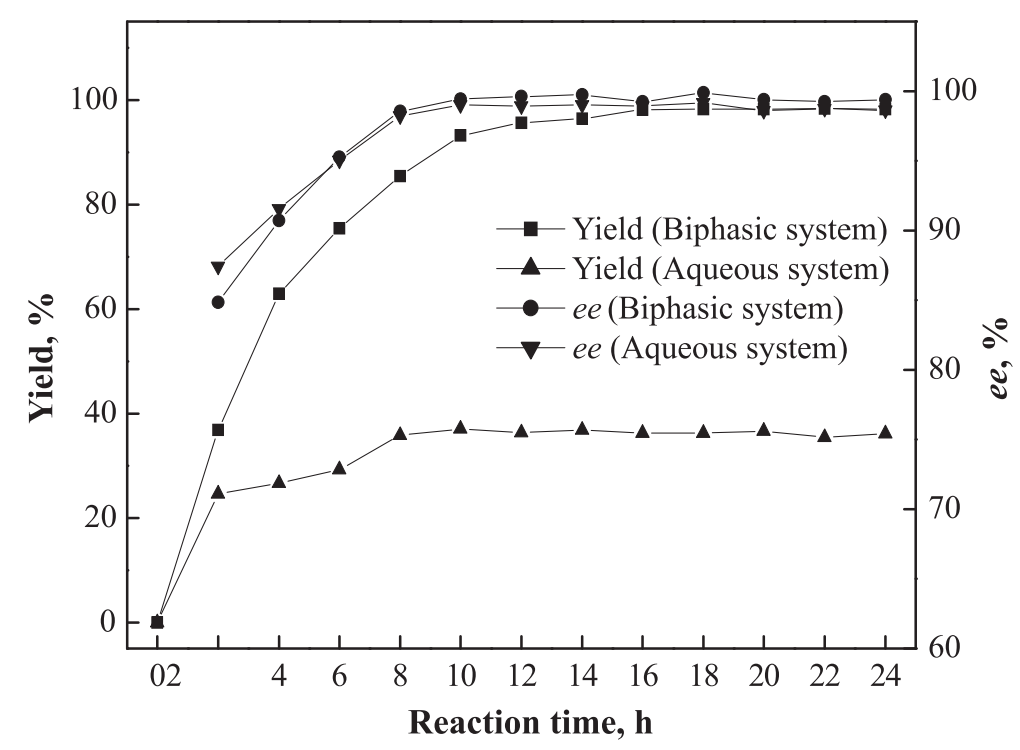

Figure 6 Time courses of the asymmetric reduction of OPBE to $(\boldsymbol{R})$-HPBE. Time courses of the asymmetric reduction of OPBE to (R)-HPBE in a monophasic aqueous system and in the aqueous/isooctane biphasic system. Reaction conditions: $1.5 \mathrm{~g}$ wet cells suspended in $10 \mathrm{~mL}$ PBS (0.1 $\mathrm{M}, \mathrm{pH}$ 7.5) containing $1.0 \mathrm{~g}$ glucose mixed with $10 \mathrm{~mL}$ isooctane containing $2 \mathrm{mmol} O P B E$ incubated at $35^{\circ} \mathrm{C}$ and $180 \mathrm{rpm}$. The monophasic aqueous system was $20 \mathrm{~mL}$ PBS (0.1 M, pH 7.0) containing $1.0 \mathrm{~g}$ glucose and $0.4 \mathrm{mmol}$ OPBE.

effect on the reaction rate and thus yield, which increased to approximately $98 \%$ with increasing the cell concentration to $0.075 \mathrm{~g} / \mathrm{mL}$. Further increasing of the cell concentration had no effect on the yield.

\section{Effects of substrate concentration}

The substrate concentration in a reaction medium affects not only the reaction rate but also the enantioselectivity of the reaction [27]. Therefore, it is of great importance to investigate the effect of substrate concentration on the OPBE asymmetric reduction in the aqueous/isooctane biphasic system. Experiments with different initial substrate concentrations from 100 to $350 \mathrm{mM}$ were conducted to investigate the effects of the substrate concentration on the asymmetric reduction of OPBE to $(R)-\mathrm{HPBE}$ under the optimal conditions obtained above. With the OPBE concentration increasing from 100 to $300 \mathrm{mM}$, the productivity increased from 10.2 to $20.3 \mathrm{~g} / \mathrm{L} /$ day, although the yield reduced from $98 \%$ to $65 \%$ (Figure 5 ). When the substrate concentration was $350 \mathrm{mM}$, both yield and productivity decreased to $42 \%$ and $15.3 \mathrm{~g} / \mathrm{L} /$ day, respectively, indicating that a high OPBE concentration $(>300 \mathrm{mM})$ would significantly inhibit the catalytic activity of cells even in the biphasic system. However, no significant influence on the enantioselectivity was observed at high concentrations of both substrate and product, and the ee value of product was consistently above $99.0 \%$.

\section{Comparison of the aqueous/organic solvent biphasic} system with the monophasic aqueous system

The reaction in the aqueous/isooctane biphasic system was compared with that in the monophasic aqueous

Table 2 Comparison between $R$. mucilaginosa CCZU-G5 and other reported microorganisms

\begin{tabular}{|c|c|c|c|c|c|c|}
\hline Strain & Reaction media & OPBE conc & Reaction time (h) & ee $(\%)$ & Yield (conversion) (\%) & References \\
\hline \multirow[t]{3}{*}{ R. mucilaginosa CCZU-G5 } & Aqueous phase & $20 \mathrm{mM}$ & 8 & $99.2(R)$ & 76.3 & This study \\
\hline & Aqueous/isooctane & $100 \mathrm{mM}^{\mathrm{a}}$ & 12 & $>99.0(R)$ & 98.3 & This study \\
\hline & & $200 \mathrm{mM}^{\mathrm{a}}$ & & & $>80$ & \\
\hline Saccharomyces cerevisiae & Water/benzene & $400 \mathrm{mM}$ & 48 & $87.5(R)$ & $(41.9)$ & Shi et al., 2009 [28] \\
\hline \multirow[t]{2}{*}{ Candida krusei SW2026 } & Water/dibutyl phthalate & $100 \mathrm{mM}$ & 16 & $97.4(R)$ & 82 & Zhang et al., 2009 [8] \\
\hline & Aqueous phase & $10 \mathrm{mM}$ & 14 & $99.7(R)$ & 95.1 & \\
\hline Candida boidinii CIOC21 & Aqueous phase & $20 \mathrm{mM}$ & 12 & $99.0(R)$ & 92 & Chen et al., 2009 [12] \\
\hline Pichia angusta & Aqueous phase & $0.14 \%$ in volume & 24 & $81(R)$ & $(100)$ & Lacerda et al., 2006 [7] \\
\hline
\end{tabular}

${ }^{\mathrm{a}}$ Based on the total volume of the whole biphasic system. 
system. As shown in Figure 6, the reaction in the monophasic aqueous system with $100 \mathrm{mM}$ OPBE stopped after $8 \mathrm{~h}$ with a low yield (36.1\%) and low productivity $(11.4 \mathrm{~g} / \mathrm{L} /$ day), which can be attributed to the substrate and product inhibition. In contrast, the reaction reached a high yield of $98.3 \%$ and a high productivity of $20.4 \mathrm{~g} / \mathrm{L} /$ day after $12 \mathrm{~h}$ in the aqueous/isooctane biphasic system. Apparently, using isooctane as the substrate carrier eliminated the substrate inhibition and enhanced the reaction rate in the biphasic system. In addition, the in situ extraction of the product from the aqueous phase to the organic phase also decreased the product inhibition and allowed the reaction to continue until almost all substrate had been converted to the product, thus resulting in a high yield (98.3\%) in the aqueous/isooctane biphasic system. Furthermore, the optical purity of the product has not changed (>99\% $e e)$ by introducing isooctane as the organic phase. It is noted that the reaction rate in the aqueous/isooctane biphasic system could be limited by mass transfer between the two phases [27], which can be increased by increasing the interfacial area between the two phases. Overall, the aqueous/isooctane biphasic system is advantageous for the asymmetric reduction of OPBE catalyzed by the microbial cells.

To date, only a few microorganisms have been described as efficient biocatalysts in the reduction of OPBE to $(R)$-HPBE. Table 2 compares the performances of the reported strains and $R$. mucilaginosa CCZU-G5 as biocatalysts in the preparation of $(R)$ HPBE from OPBE. Although excellent yield and ee value can be obtained with $C$. krusei SW2026 and C. boidinii CIOC21 in aqueous phase systems $[8,12]$, the low substrate loading restricted their industrial applications. To increase the substrate concentration, Zhang et al. employed a water/dibutyl phthalate biphasic system [8]. Although the concentration of OPBE increased ninefold, the product yield decreased from $95.2 \%$ to $82 \%$. To the best of our knowledge, only Shi et al. reduced OPBE at as high as $0.4 \mathrm{M}$ with $\mathrm{S}$. cerevisiae in water/benzene biphasic system [28]. However, the conversion of OPBE and $e e$ of $(R)-\mathrm{HPBE}$ were only $41.9 \%$ and $87.5 \%$, respectively. Moreover, the reaction time was very long. When the reduction of OPBE (100 $\mathrm{mM})$ was carried out with $R$. mucilaginosa CCZU-G5 in aqueous/isooctane biphasic system, the shortest reaction time, excellent $e e$ and product yield were achieved in the present study. Even if the concentration of OPBE was increased to $200 \mathrm{mM}$, the yield was still over $80 \%$, and the ee was not affected. Compared with other strains listed in Table 2, R. mucilaginosa CCZU-G5 is a more competitive and promising biocatalyst for asymmetric reduction of OPBE to $(R)$ HPBE.

\section{Conclusions}

In this study, an aqueous/isooctane biphasic system was successfully established for asymmetric reduction of OPBE to $(R)$-HPBE with a newly isolated strain $R$. mucilaginosa CCZU-G5. Several factors such as volume ratio of the aqueous phase to the organic phase, reaction temperature, reaction $\mathrm{pH}$, cell concentration, and substrate concentration significantly influenced the reaction rate and product yield. However, the optical purity of the product was not significantly affected and maintained at high levels of $>99 \%$. Under optimum reaction conditions $\left(35^{\circ} \mathrm{C}, \mathrm{pH} 7.5,0.075 \mathrm{~g} / \mathrm{mL}\right.$ of cells, $100 \mathrm{mM}$ OPBE, 1:1 of volume phase ratio), $R$. mucilaginosa CCZU-G5 exhibited excellent catalytic capability, giving product an excellent yield (98.3\%) and $e e(>99 \%)$.

\section{Competing interests}

The authors declare that they have no competing interests.

\section{Authors' contributions}

L-QW designed the study and drafted the manuscript. Z-QW revised the manuscript. QQ provided the experimental guidance. S-TY provided the experimental guidance and manuscript revision. J-JM and L-JW conducted the experiments and drafted the manuscript. All authors read and approved the final manuscript.

\section{Acknowledgements}

This work was supported by National Natural Science Foundation of China (No. 21102011) and the Science and Technology Supporting Project of Changzhou (No. CE20145041).

Received: 15 December 2014 Accepted: 21 January 2015

Published online: 18 February 2015

\section{References}

1. Herold P, Indolese AF, Studer M, Jalett HP, Siegrist U, Blaser HU (2000) New technical synthesis of ethyl (R)-hydroxy-4-phenylbutyrate of high enantiomeric purity. Tetrahedron 56:6497-6499

2. Iwasaki G, Kimura R, Numao N, Konda K (1989) A practical and diastereoselective synthesis of angiotensin converting enzyme inhibitors. Chem Pharm Bull 37:280-283

3. Zhang W (2009) Biocatalytic synthesis of ethyl (R)-2-hydroxy-4phenylbutyrate. MS thesis. Jiangnan University, China

4. Liese A, Kraal U, Kierkelsc H, Schulze B (2002) Membrane reactor development for the kinetic resolution of ethyl 2-hydroxy-4-phenylbutyrate. Enzyme Microb Technol 30:673-681

5. Huang SH, Tsai SW (2004) Kinetic resolution of (R, S)-ethyl 2-hydroxyl-4phenylbutyrate via lipase-catalyzed hydrolysis and transesterification in isooctane. J Mol Catal B Enzym 28:65-69

6. Kaluzna I, Andrew AA, Bonilla M, Martzen MR, Stewart JD (2002) Enantioselective reductions of ethyl 2-oxo-4-phenylbutyrate by Saccharomyces cerevisiae dehydrogenases. J Mol Catal B Enzym 17:101-105

7. Lacerda PSB, Ribeiro JB, Leite SGF, Ferrara MA, Coelho RB, Bon EPS, Lima ELS, Antunes OAC (2006) Microbial reduction of ethyl 2-oxo-4-phenylbutyrate Searching for R-enantioselectivity. New access to the enalapril like ACE inhibitors. Tetrahedron Asymmetry 17:1186-1188

8. Zhang W, Ni Y, Sun ZH, Zheng P, Lin WQ, Zhu P, Ju NF (2009) Biocatalytic synthesis of ethyl (R)-2-hydroxy-4-phenylbutyrate with Candida krusei SW2026: a practical process for high enantiopurity and product titer. Process Biochem 44:1270-1275

9. Wang W, Zong MH, Lou WY (2009) Use of an ionic liquid to improve asymmetric reduction of 4-methoxyacetophenone catalyzed by immobilized Rhodotorula sp. AS2.2241 cells. J Mol Catal B Enzym 56:70-76

10. Chadha A, Manohar M, Soundararajan T, Lokeswari TS (1996) Asymmetric reduction of 2-oxo-4-phenylbutanoic acid ethyl ester by Daucus carota cell cultures. Tetrahedron Asymmetry 7:1571-1572 
11. Dao DH, Kawai Y, Hida K, Hornes S, Nakamura K, Ohna A, Okamura M, Akasaka T (1998) Stereochemical control in microbial reduction. 30. Reduction of alkyl 2-oxo-4-phenylbutyrate as precursors of angiotensin converting enzyme (ACE) inhibitors. Bull Chem Soc Jpn 71:425-432

12. Chen $Y Z$, Lin H, Xu XY, Xia XY, Wang LX (2009) Preparation the key intermediate of angiotensin-converting enzyme (ACE) inhibitors: high enantioselective production of ethyl ( $R$ )-2-hydroxy-4-phenylbutyrate with Candida boidinii CIOC21. Adv Synth Catal 350:426-430

13. Gong PF, Xu JH (2005) Bio-resolution of a chiral epoxide using whole cells of Bacillus megaterium ECU1001 in a biphasic system. Enz Microb Technol 36:252-257

14. He JY, Sun ZH, Ruan WQ, Xu Y (2006) Biocatalytic synthesis of ethyl (S)-4chloro-3-hydroxy-butanoate in an aqueous-organic solvent biphasic system using Aureobasidium pullulans CGMCC 1244. Process Biochem 41:244-249

15. Kansal H, Banerjee UC (2009) Enhancing the biocatalytic potential of carbonyl reductase of Candida viswanathii using aqueous-organic solvent system. Bioresour Technol 100:1041-1047

16. Jiang Q, Yao SJ, Mei LH (2002) Tolerance of immobilized baker's yeast in organic solvents. Enz Microb Technol 30:721-725

17. Vermue M, Sikkema J, Verheul A, Bakker R, Tramper J (1993) Toxicity of homologous series of organic solvents for the gram-positive bacteria Arthrobacter and Norcardia sp. and the gram-negative bacteria Acietobacter and Pseudomonas sp. Biotechnol Bioeng 42:747-758

18. Gu LQ, Wei HF, Zhang XC, Xu G, Ma L (1998) Bioreduction of quinine derivatives by immobilized baker's yeast in hexane. Chin J Chem 16:45-50

19. Li AT, Zhang JD, Yu HL, Pan J, Xu JH (2011) Significantly improved asymmetric oxidation of sulfide with resting cells of Rhodococcus sp. in a biphasic system. Process Biochem 46:689-694

20. Pan J, Dang ND, Zheng GW, Cheng B, Ye Q, Xu JH (2014) Efficient production of I-menthol in a two-phase system with SDS using an immobilized Bacillus subtilis esterase. Bioresources and Bioprocessing 1:12

21. Fernandes $P$, Vidinha $P$, Ferreira $T$, Silvestre $H$, Cabral JMS, Prazeres DMF (2002) Use of free and immobilized Pseudomonas putida cells for the reduction of a thiophene derivative in organic media. J Mol Catal B Enzym 19-20:353-361

22. Philips RS (1996) Temperature modulation of the stereochemistry of enzymatic catalysis: prospects for exploitation. Trends Biotechnol 14:13-16

23. Hage A, Schoemaker HE, Field JA (2001) Optimization of stereoselective ketone reduction by the white-rot fungus Merulius tremellosus ono991. Appl Microbiol Biotechnol 57:79-84

24. Katz M, Sarvary I, Frejd T, Hahn-Hagerdal B, Gorwa-Grauslund MF (2002) An improved stereoselective reduction of a bicyclic diketone by Saccharomyces cerevisiae combining process optimization and strain engineering. Appl Microbiol Biotechnol 59:641-648

25. Patel RN, Robison RS, Szarka LJ, Kloss J, Thottathil JK, Mueller RH (1991) Stereospecific microbial reduction of 4,5-dihydro-4-(4-methoxyphenyl)-6(trifluoromethyl-1H-1)-benzazepin-2-one. Enz Microb Technol 13:906-912

26. Kianmehr A, Pooraskari M, Mousavikoodehi B, Mostafavi SS (2014) Recombinant D-galactose dehydrogenase partitioning in aqueous twophase systems: effect of $\mathrm{pH}$ and concentration of PEG and ammonium sulfate. Bioresources and Bioprocessing 1:6

27. Shimizu S, Kataoka M, Katoh M, Morikawa T, Miyoshi T, Yamada H (1990) Stereoselective reduction of ethyl 4-chloro-3-oxobutanoate by a microbial aldehyde reductase in an organic solvent-water diphasic system. Appl Environ Microbiol 56:2374-2377

28. Shi YG, Fang Y, Wu HP, Li F, Zuo XQ (2009) Improved production of ethyl(R)-2-hydroxy-4-phenylbutyrate with pretreated Saccharomyces cerevisiae in water/organic solvent two-liquid phase systems. Biocatal Biotransfor 27:211-218

\section{Submit your manuscript to a SpringerOpen ${ }^{\circ}$ journal and benefit from:}

- Convenient online submission

- Rigorous peer review

- Immediate publication on acceptance

- Open access: articles freely available online

- High visibility within the field

- Retaining the copyright to your article

Submit your next manuscript at $>$ springeropen.com 